\title{
AS LISBOAS DA HISTÓRIA DE UM CERCO: CIDADE, MEMÓRIA E LITERATURA EM SARAMAGO
}

Maristela Kirst de Lima Girola ${ }^{1}$

RESUMO: O presente ensaio tem como objetivo tecer e discutir algumas reflexões sobre a construção ficcional das personagens e do espaço da cidade em História do cerco de Lisboa, de José Saramago, considerando as relações entre literatura, história e memória.

PALAVRAS-CHAVE: José Saramago, Romance, Espaço, Memória, Personagem.

THE LISBONS OF THE HISTORY OF A SIEGE: CITY, MEMORY AND LITERATURE IN SARAMAGO

ABSTRACT: This essay aims to propose and discuss some aspects about the construction of the characters and the fictional space in História do cerco de Lisboa, by José Saramago, considering the relations between literature, history and memory.

KEYWORDS: José Saramago, Novel, Space, Memory, Character.

\footnotetext{
${ }^{1}$ Doutora egressa do Programa de Pós-Graduação em Letras da Pontifícia Universidade Católica do Rio Grande do Sul-PUCRS, tendo defendido tese na área de Literatura Portuguesa, em janeiro de 2012.
} 
Para Eduardo Lourenço, José Saramago, ao lado de António Lobo Antunes, é um dos grandes expoentes literários do pós-abril de 1974: "Como se nesse momento, quer dizer, depois de 75, entre 75 e 80, Portugal, a consciência portuguesa, a imaginação portuguesa, o imaginário português quisessem desenhar um outro mapa." (LOURENÇO, 2004, p. 349). Em História do cerco de Lisboa, José Saramago coloca em discussão a questão da portugalidade, recuperando e reelaborando um emblemático momento histórico; apontado como possível gérmen de um posterior sentimento nacional, a tomada de Lisboa dos muçulmanos pelo cavaleiro cristão, Afonso Henriques.

O personagem Raimundo Silva, revisor, é tomado pela tentação de alterar o sentido de um livro de História, colocando um 'não' no lugar de um 'sim', dizendo que os cruzados não ajudaram os portugueses no cerco a Lisboa. Como revisor, deveria seguir certas normas de conduta, assim, viola o seu campo semântico inicial (LOTMAN, 1978), rompendo com a postura que se espera de um profissional como ele. Essa atitude traz complexidade à personagem e estabelece o conflito que dá início ao romance de Saramago, desencadeando o enredo.

Tal ato terá reflexos que serão desenvolvidos ao longo da obra e trará, como consequência, a entrada da personagem Maria Sara, a supervisora chefe dos revisores, à trama. É da personagem feminina que partirá o estímulo necessário para que Raimundo dê continuidade ao seu questionamento histórico, transformando-o na escrita de uma nova versão da história do cerco de Lisboa, pois há:

[uma] reescrita que estrutura a construção do romance, ao evidenciar a coexistência de um discurso outro, ideologicamente subversivo, que vem necessariamente abalar a verdade inerente ou decorrente da historiografia oficial. (MARTINS et alli, 2005, p. 19)

Para Maria Odete Santos Jubilado, "Saramago revisita de maneira crítica a História oficial, tendo consciência da lacuna que existe entre o desejo de reconstruir o passado e a impossibilidade real de consegui-lo totalmente." (JUBILADO, 2000, p. 61). O conflito da personagem Raimundo representa a discussão do próprio espaço da escrita como um espaço de estabelecimento de verdades históricas ${ }^{2}$ :

\footnotetext{
${ }^{2}$ Sandra Pesavento explica que "Michel de Certeau, por exemplo, discorrendo sobre o que chama de 'a operação historiográfica' - prática que liga a ideia ao lugar da escrita e que tem como resultado um discurso sobre o passado - acentuava a importância da subjetividade no processo do 'fazer história'. Para o autor, entre a pretensão de objetividade da construção narrativa da história e a realidade do sujeito que escreve, que ocupa um lugar social e cultural no mundo, que é portador de um saber e do horizonte de
} 
Que volta dará a editora ao seu destino de revisor faltoso, como irá ela punir o insolente atentado contra a solidez dos fatos históricos, a qual pelo contrário, deve ser permanentemente reforçada, defendida de acidentes, sob pena de perdermos o sentido da nossa própria atualidade. (SARAMAGO, 1989, p. 79).

Durante um passeio pela região de Lisboa, onde mora, nos arredores do Castelo de São Jorge, Raimundo põe-se a imaginar como os portugueses tomarão a cidade dos mouros, agora, sem a ajuda dos cruzados:

que se avenham como puderem, com as suas parcas forças nacionais, se nacionais já podemos chamar-lhes (...) para Raimundo Silva, e até nova ordem ou até que Deus Nosso Senhor doutra maneira o disponha, Lisboa continua a ser de mouros (SARAMAGO, 1989, p. 60-61).

Raimundo encontra-se a caminhar justamente nos lugares da antiga cidade moura. $\mathrm{Na}$ mente de Raimundo, a atual e a antiga Lisboa se misturam, "coincidência histórica e topográfica, uma consciência múltipla, caleidoscópia" (SARAMAGO, 1989, p. 60). De acordo com José Joaquín Parra Bañón, nos romances de Saramago, Lisboa

será la única residencia para sus solitarios, la que citada o no, se multiplique en todas sus novelas. No Lisboa absoluta, sino el fragmento que de ella cada personaje siente de su propiedad, el espacio sentimental que es como una prolongación de su casa. Lisboa será definida cartográficamente, indicándose con precisión los sítios y los nombres (...) No es la ciudad turística la que le interesa, sino la ciudad como ser vivo sometido al tiempo y como álbum de la memoria personal. (BAÑÓN, 2006, p. 222).

O passeio de Raimundo pela região histórica do castelo não consiste só em um deslocamento espacial, mas numa travessia temporal, em que passado e presente se mesclam, em que ele percebe os rastros da História, os vestígios de duas culturas: a moura e a portuguesa. Coexistem, num terceiro momento histórico, que é o presente narrativo, duas épocas e dois espaços, a Lissobona moura e a Lisboa lusa.

Faz-se pertinente aqui lembrar o conceito de rastro ${ }^{3}$ proposto por Paul Ricoeur,

expectivas de sua época, instala-se um comprometimento de metas. Ou seja, aniquila-se a pretensão da verdade objetiva." (PESAVENTO, 2006, p. 4).

${ }^{3}$ Conforme Ricoeur, o passado deixa um rastro, por meio dos monumentos e dos documentos. O rastro apresenta duas dimensões temporais: por um lado, é visível no aqui e no agora, como vestígio, como marca; por outro lado, há rastro, já que, antes, alguém passou por aqui, o que pressupõe, assim, a anterioridade. $\mathrm{O}$ vestígio é algo que permanece, pois os homens do passado deixam as suas marcas, os produtos de suas atividades, de suas obras: "Tudo isso é a História. Dizer que ela é um conhecimento por rastros, é apelar, em último recurso, para a significância de um passado findo que, no entanto, permanece preservado em seus vestígios." (RICOEUR, 1997, p. 201). Se é possível dizer-se que certas coisas provêm do passado, é porque o dasein (intervalo entre a vida e a morte, entremeio, preocupação) traz 
como conector entre as perspectivas sobre o tempo e um requisito para a prática historiadora. Seguir o rastro é, ao mesmo tempo, uma maneira de contar com o tempo e decifrar, no espaço, o estiramento do tempo. Nesse contexto, em que lugar se situa a personagem? Eis a indagação que conduz a trajetória de descoberta do herói. A localização da casa de Raimundo, onde ficava a muralha com o portão de ferro, pode ser entendida como um 'entre lugar', onde o passado ainda se faz atuante:

Apercebe-se, pela primeira vez com evidência luminosa, de que mora no preciso lugar onde antigamente se abria a Porta de Alfofa, se da parte de dentro ou da parte de fora eis o que hoje não se pode averiguar e impede que saibamos, desde já, se Raimundo Silva é um sitiado ou um sitiante, vencedor futuro ou perdedor sem remédio. (SARAMAGO, 1989, p. 75).

O revisor, agora escritor, visita o castelo de São Jorge, de onde observa Lisboa: "Raimundo Silva quer ver a cidade, ainda não sabe para quê" (SARAMAGO, 1989, p. 133). O espaço histórico é percorrido pela personagem:

Raimundo Silva aproxima-se do muro, olha para baixo e ao longe, os telhados, as regiões superiores das fachadas e das empenas, à esquerda o rio sujo de barro, o arco triunfal da Rua Augusta, a confusão das ruas quadriculadas, um ou outro canto duma praça, as ruínas do Carmo, as outras que ficaram do incêndio (...). Entrou no castelo (...) conhece os caminhos, vai subir à muralha do lado de $\mathrm{S}$. Vicente, ver daí a disposição dos terrenos. (SARAMAGO, 1989, p. 134).

A nova posição espacial de Raimundo traz a informação que faltava para que ele possa escrever o seu livro. Ele se coloca como personagem na ficção histórica que engendra:

Tem a consciência da sua postura cênica, melhor dizendo, cinematográfica, a gabardina é manto medieval, os cabelos soltos plumas, e o vento não é vento, mas sim corrente de ar produzida por uma máquina (...) no seu espírito surgiu (...) o motivo tão procurado. (SARAMAGO, 1989, p. 135).

Ele descobre por que os cruzados disseram não e volta para casa a fim de escrever a sua história do cerco. As palavras do narrador colaboram com a ideia de que Saramago (des)constrói e reflete sobre a construção historiográfica de Afonso Henriques como o precursor da nacionalidade portuguesa:

D. Afonso Henriques com os seus soldados, que nossos foram,

consigo os rastros de sua proveniência. A ideia de vestígio amplia a de rastro por englobar a dialética da ausência e da presença, podendo embasar a discussão a respeito da dimensão veritativa do ato mnemônico e do ato historiográfico. 
primeiros pais da nacionalidade, pois que os antepassados deles, por terem nascido cedo demais, portugueses não tinham podido ser. Este é um ponto de genealogia que em geral não merece consideração, averiguar o que, não tendo nenhuma importância, deu vida, lugar e ocasião à importância que passou a ter o que dizemos ser importante. (SARAMAGO, 1989, p. 134).

A constituição desse gérmen da identidade nacional ou "espírito português em formação" (SARAMAGO, 1989, p.139) ocorre junto com a evolução da personagem, em planos históricos diferentes (século XII e XX), mas no mesmo plano da narrativa. Raimundo descobre o princípio do espírito nacional e se descobre como sujeito.

Quando houver escrito a sua própria história do cerco de Lisboa, Raimundo retornará ao final oficial, os portugueses vencerão. Acreditamos que o objetivo de Saramago seja propor uma discussão acerca do nacionalismo português como construção social, retomando um episódio do século XII estabelecido (escolhido) como possível momento inicial para o desenvolvimento do espírito nacional português, o ano de 1147, com a aclamação de Afonso Henriques como primeiro rei e fundador de uma nação composta por um povo dito predestinado; bem como constituir (escolher) Lisboa como cidade berço da portugalidade. Além disso, expor de que maneira um mito fundador é instituído e, a partir disso, refletir sobre o próprio fazer histórico.

$\mathrm{Na}$ história do cerco de Lisboa escrita pela personagem Raimundo, Afonso Henriques é o precursor da nação e a vitória sobre os mouros é imprescindível para que Portugal venha a existir:

D. Afonso Henriques arenga às tropas reunidas no Monte da Graça, falalhes da pátria, já então era assim, da terra natal, do futuro que nos espera, só não nos falou dos antepassados porque verdadeiramente ainda quase não os havia, mas disse, Pensai que se não vencermos esta guerra Portugal se acabará antes de ter começado, e assim não poderão ser portugueses tantos reis que estão por vir, tantos presidentes, tantos militares, tantos santos, e poetas, e ministros, e cavadores de enxada, e bispos, e navegantes, e artistas, e operários, e escriturários, e frades, e diretores. (SARAMAGO, 1989, p. 234-35).

$\mathrm{Na}$ ironia do narrador saramaguiano, podemos verificar a influência da subjetividade dos historiadores/escritores que, ao tratarem dos fatos e da memória, formam uma narrativa que carrega a sua interpretação, a sua hipótese do que teria acontecido, "a escrita e a atribuição de sentido a acontecimentos que se passaram por fora da experiência do vivido e não são mais verificáveis" (PESAVENTO, 2006, p. 6). 
Saramago joga com a "operação historiográfica", aproximando-a da ficção, por meio da narratividade. Conforme Sandra Pesavento,

história e memória partilham uma mesma feição de ser: são ambas narrativas, formas de dizer o mundo, de olhar o real. São discursos, pois. Falas que discorrem, descrevem, explicam, interpretam, atribuem significados à realidade. Como narrativas sobre algo, são representações, ou seja, são discursos que se colocam no lugar da coisa acontecida. (PESAVENTO, 2006, p. 1).

Quando Raimundo recebe de Costa, funcionário da editora, um novo trabalho - ao invés de um livro de História, a revisão de um romance -, ele fica mais calmo:

Afinal, é apenas um romance entre os romances, não tem que preocuparse mais com introduzir nele o que nele já se encontra, porque livros destes, as ficções que contam, fazem-se, todos e todas, com uma continuada dúvida, com um afirmar reticente, sobretudo a inquietação de saber que nada é verdade e ser preciso fingir que o é, ao menos por um tempo, até não se poder resistir à evidência inapagável da mudança (...) todo o romance é isso, desespero, intento frustrado de que o passado não seja coisa definitivamente perdida. Só não se acabou de averiguar se é o romance que impede o homem de esquecer-se, ou se é a impossibilidade do esquecimento que o leva a escrever romances. (SARAMAGO, 1989, p. 56).

Dentre as personagens históricas do cerco de Lisboa, Raimundo precisa escolher uma para tornar protagonista da história que está escrevendo. Coloca-se na janela de seu apartamento, nos arredores do Castelo de São Jorge, a imaginar os cavaleiros acampados:

Forte motivo temos para andar mirando a estes homens (...) encontrar por aqui alguém que possa servir de personagem (...) deixou-se ficar na sua janela da Rua do Milagre de Santo António. (SARAMAGO, 1989, p. 184).

As lutas travadas entre cristãos e mouros são descritas. O espaço é mostrado de uma forma cinematográfica, com um efeito de câmera: "E agora passemos um pouco ao longo desta fila de corpos sujos e sangrentos" (SARAMAGO, 1989, p. 284). "Vendo" e "ouvindo" as personagens dispostas no "cenário", Raimundo escolhe o cavaleiro Mogueime.

\footnotetext{
${ }^{4}$ Pesavento, apoiando-se em Certeau, explica que “a operação historiográfica (...) é animada por um desejo de verdade, produzindo resultados de verossimilhança e credibilidade através de um discurso que se legitima pela autoridade da fala, pela lógica de argumentação e da retórica e pelas evidências da pesquisa, como as citações, as notas de rodapé, a bibliografia e o arrolamento de fontes, a desafiar o leitor ainda incrédulo a refazer o mesmo caminho percorrido pelo historiador." (PESAVENTO, 2006, p. 6).
} 
David Perkins, ao abordar a construção da narrativa histórica, em seu texto História da literatura e narração, procura identificar semelhanças estruturais entre as narrativas históricas e literárias, como a presença de um narrador, a construção de um herói ou sujeito lógico, e a organização dos eventos em um enredo, com início, meio e fim. Por exemplo, o historiador, assim como o literato, descreve "a transição através do tempo, de um estado de coisas a outro diferente, e um narrador nos conta essa mudança”" (PERKINS, 1999, p. 1). De acordo com Perkins, a história narrativa assemelha-se à narrativa tradicional, pois apresenta uma entidade, um herói, que sofre uma transição. A inter-relação dos eventos narrativos segue uma estrutura de premissa e consequência. Algum tipo de enredo deve existir. Assim, o fecho de uma história é artificial, da mesma forma que o início, pois "não há clareza sobre exatamente quando, ou se, sua história terminou" (PERKINS, 1999, p. 11). Por isso, o personagem historiador/escritor de Saramago precisa estipular um momento inicial para o sentimento nacional a respeito da história que pretende narrar.

Em História do cerco de Lisboa, temos a figura do escritor, personificada na personagem Raimundo, que surge da "explosão da história-memória” e representa “a ligação estreita, íntima e pessoal que (...) mantém com seu sujeito (...) a proclamá-lo, a aprofundá-lo e a fazer, não o obstáculo, mas a alavanca de sua compreensão", já que "esse sujeito deve tudo a sua subjetividade, sua criação, sua recriação" (NORA, 1993, p. 20). Percebe-se no romance a preocupação em contrariar a leitura e a interpretação da história do país mostrada "pela via exclusiva da linguagem oficial que se forma no espaço generalizado da rua, espaço das nossas instituições públicas" e que apresenta um discurso “normativo” (DAMATTA, 1989, p. 120).

Essa memória institucionalizada é chamada por Pesavento de "memória cívica", uma vez que o Estado, a educação e a historiografia funcionam como "legitimadores de uma memória, ou seja, sacralizam aquilo que deve ser lembrado e também o que deve ser esquecido.” (PESAVENTO, 2006, p. 5). A literatura, por sua vez, é uma forma diferente de memória, como explica Maria Jesús Fernández García, pois o que oferece "é uma representação desobjetivadora e uma memória alternativa à memória e esquecimento oficiais." (GARCÍA, 2010, p. 507). Se “cada memória individual é um ponto de vista sobre a memória coletiva", o ponto de vista pode mudar "segundo o lugar que nele ocupo e, que por sua vez, esse lugar muda segundo as relações que mantenho com outros meios" (RICOEUR, 2007, p. 133-34). 
A escrita de uma nova história do cerco de Lisboa, com o protagonismo de Mogueime e de sua amada Ouroana, entretanto, também corrobora para a escrita de uma outra história que se compõe, concomitantemente, isto é, a história de amor de Raimundo e Maria Sara. Esclarece Maria Alzira Seixo:

a História é, portanto, o Livro; e daí que todo o livro tenha de se remeter à História. É certo que este é, nos romances de Saramago, aquele onde o discurso da História mais lugar ocupa, tendo, no entanto, uma ocupação diegética reduzidíssima, quase inexistente, tornada símbolo ou pretexto indicial de formulação da intriga. Isto é: o que efetivamente acontece, no universo ficcional, é o namoro de Raimundo e Maria Sara, os dois funcionários da editora que publica o livro História do Cerco de Lisboa; se isso acontece, porém, é porque Raimundo praticou um erro na revisão das provas e, desse erro, vai surgir a presença da doutora Maria Sara na editora e a sua (dele) outra escrita do mesmo sucesso. (SEIXO, 1999, p. 75).

A crítica portuguesa prossegue, ressaltando:

a história a partir desse 'não' é já uma ficção, uma história de amor, porque se faz por amor e de amor - personagens vão emergir desse cerco, Mogueime e Ouroana, que representarão, nesse tempo da fundação da história nacional, e noutro plano da narrativa, a própria história de amor entre Raimundo e Maria Sara. (SEIXO, 1999, p. 76).

O apartamento de Raimundo Silva transforma-se pouco a pouco com a presença de Maria Sara que adentra esse universo antes masculino e solitário:

De repente sentiu calor apesar de não ter o aquecimento eléctrico ligado, desatou o cinto do roupão, levantou-se da cadeira, estes movimentos (...) eram apenas a expressão de um inesperado bem-estar, um vigor quase cósmico, uma tranquilidade de deus sem remorsos. A casa tornouse subitamente pequena, até a própria janela aberta para as três vastidões, a da cidade, a do rio, a do céu. (SARAMAGO, 1989, p. 96).

Segundo Bañón, nos romances saramaguianos, podemos identificar dois tipos de casa: "la que es padecida por el hombre em soledad y la que es habitada en comunión por la família.” (BAÑÓN, 2006, p. 214-15). A casa de Raimundo Silva enquadra-se no primeiro tipo e é também "el recinto bélico en el que por primera vez descubre la casa carnal y compasiva de María Sara” (BAÑóN, 2006, p. 215). Para Bañón, os homens solitários de Saramago parecem

huéspedes de su casa, casi asilados que a duras penas se soportan a si mismos y a sus cosas. En sus conflictos y en su austeridad, en la 
enajenación del habitante respecto a ella y sus contenidos, tienen algo que ver con las celdas conventuales. (BAÑ́́N, 2006, p. 215).

O cerco da cidade de Lisboa torna-se metáfora do cerco amoroso. Por exemplo, quando Maria Sara promete visitar Raimundo Silva e pergunta o que ele fará quando desligarem o telefone, ele diz que irá rezar para que os mouros não ataquem na calada da noite: “Tremo de pavor, Tanto, Antes de vir para esta guerra, eu era apenas um revisor (...) não vim de tão longe para morrer diante dos muros de Lisboa" (SARAMAGO, 1989, p. 246).

No primeiro encontro, na casa de Raimundo, a pedido de Maria Sara, ele abre a janela. Lado a lado, apreciam a paisagem da cidade de Lisboa. Ele conta que eles estão precisamente onde antes ficava uma das torres de observação da cidade sitiada, do lado de dentro: "Aqui, na torre, que somos nós, mouros ou cristãos, Por enquanto, mouros, estamos cá justamente para impedir que os cristãos entrem, Não o conseguiremos" (SARAMAGO, 1989, p. 267). Ela pede-lhe um beijo: "As bocas abriram-se ligeiramente, de súbito o beijo total, intenso, ansioso" (SARAMAGO, 1989, p. 274). Seixo entende a janela, elemento arquitetônico recorrente no romance, como

símbolo de uma desobstrução (social, psicológica), vai ser dedicada à 'visão' de um cerco (trata-se não só de cercar Lisboa mas de cercar o livro, e de cercar o corpo de Maria Sara, de cercar enfim as suas hipóteses de ser humano). Ao contrário da janela, o cerco é justamente uma ameaça de oclusão e entretece relações dúbias com o paradigma esconder/mostrar. É claro que a janela também 'cerca', mas cerca para melhor fazer ver e não para destruir, cerca para isolar, e como que para engrandecer, como numa lente, e talvez por isso algumas das simpatias do narrador e da sua amada vão mais para os mouros sitiados do que para os cristãos sitiantes, eles próprios se sentindo cercados, e em duplo sentido, ou pela própria força amorosa que os concentra em si mesmos, e os leva para junto da janela (fase do primeiro encontro amoroso), ou pela circunstância social que sempre cria problemas e que só o amor resgata. (SEIXO, 1999, p. 79).

Bañón, por sua vez, enfatiza a janela como um dos elementos fundamentais da arquitetura romanesca saramaguiana:

se asomará el escritor por las ventanas privilegiadas de sus personajes, por esos filtros transgredibles en ambas direcciones. En ellas se representa el espectáculo del mundo y se verifica la permanencia mutante del paisage. Sus ventanas nunca son neutras: son estados de ánimo (...) La ventana significa el contacto con el médio, la posibilidad de compartilo, el lugar de confluência de la ciudad y la intimidad. Es el lugar de la interrogación. (BAÑÓN, 2006, p. 218). 
O cerco entre Raimundo e Maria Sara, finalmente, chega ao fim, assim como o cerco de Lisboa. Para Maria Sara, o amor e a guerra guardam semelhanças: "Estamos em guerra, e é guerra de sítio, cada um de nós cerca o outro e é cercado por ele, queremos deitar abaixo os muros do outro e continuar com os nossos" (SARAMAGO, 1989, p. 330), mas o amor surge mesmo quando as barreiras de ambos os lados caem e, assim, "o amor é o fim do cerco" (SARAMAGO, 1989, p. 330). Com isso, Lisboa torna-se também o corpo da amada, cidade agora percorrida pelas mãos de Raimundo:

Agora a memória dos dedos pôde reconhecer a macieza do tecido da blusa em que tocava pela primeira vez, a sensação foi rapidíssima e no mesmo instante diluída pela consciência tumultuosa de que sob a mão banal do homem estava o prodígio de um seio. Aturdido pelo contacto, Raimundo Silva levantou a cabeça, queria olhar, ver, saber, ter a certeza de que era a sua própria mão que ali estava, agora sim, o muro invisível desmoronava-se, para além dele ficava a cidade do corpo, ruas e praças, sombras, claridades, um cantar que vem não se sabe donde, as infinitas janelas, a peregrinação interminável. (SARAMAGO, 1989, p. 293-94).

O leitor acompanha o que as mãos de Raimundo tocam e o que os seus olhos veem. A fusão de seus corpos acontece em sintonia, "gemeram juntos" (SARAMAGO, 1989, p. 295), é um momento de integração com a cidade, com o mundo, metaforizado pelo narrador com muito erotismo e beleza, sem esquecer-se das águas que envolvem (as) Lisboa(s): "Quando surdamente gritaram, quando as comportas do dilúvio se abriram sobre a terra e as águas da terra, e depois a calma, o largo estuário do Tejo" (SARAMAGO, 1989, p. 295).

\section{Bibliografia:}

BAÑÓN, José Joaquín Parra. Arquitectura de palabras/palabras de arquitectura. Sobre José Saramago, la casa e el laberinto. In: MARTINS, Adriana Alves de Paula; SABINE, Mark: Dialogue with Saramago: essays in comparative literature. Lisboa: Fundação Luso Americana e Calouste Gulbekian. Manchester Spanish e Portuguese Studies, 2006.

DAMATTA, Roberto. O que faz o brasil, Brasil? Rio de Janeiro: Rocco, 1989.

GARCIA, Maria Jesús Fernández. Memória literária dos ditadores em Espanha e Portugal. In: ALVES, Fernanda Mota. TAVARES, Sofia. SOEIRO, Ricardo Gil. PASQUALE, Daniela Di. (Orgs.) Filologia, memória e esquecimento. ACT 20. Centro de Estudos Comparatistas, Universidade de Lisboa. Ribeirão: Húmus, 2010. 
JUBILADO, Maria Odete Santos. Saramago e Sollers. Uma (re)escrita irônica? Lisboa: Veja, 2000.

LOURENÇO, Eduardo. Divagação em torno de Lobo Antunes. In: Colóquio Internacional António Lobo Antunes, Évora, 2002. A escrita e o mundo em António Lobo Antunes (actas do Colóquio Internacional António Lobo Antunes). Lisboa: Dom Quixote, 2004.

MARTINS, Lourdes Câncio. CARVALHO, Célia. SANTOS, Paula Pires. SILVA, Helena. Reler José Saramago: Paradigmas ficcionais. Chamusca: Cosmos, 2005.

NORA, Pierre. Entre memória e história: a problemática dos lugares. Tradução de Yara Aun Khoury. Revista Projeto História. São Paulo: Departamento de História da Pontifícia Universidade Católica de São Paulo, n. 10, 1993, p. 7.

PERKINS, David. História da Literatura e Narração. In: Cadernos do Centro de Pesquisas Literárias da PUCRS, Porto Alegre, v. 3, n. 1, mar. 1999. Série Traduções.

PESAVENTO, Sandra Jatahy. Palavras para crer: Imaginários de sentido que falam do passado. Nuevo mundo Mundos nuevos, Debates (puesto em línea el 28 enero de 2006.) Disponível em: http://nuevomundo.revues.org/1499. Acesso em 25 de fevereiro de 2011.

RICOEUR, Paul. A memória, a bistória e o esquecimento. Trad. Alain François Campinas: Unicamp, 2007.

. Tempo e narrativa. Tomo III. Trad. Roberto Leal Ferreira. Campinas:

Papirus, 1997.

SARAMAGO, José. História do Cerco de Lisboa. São Paulo: Companhia das Letras, 1989.

SEIXO, Maria Alzira. Lugares da fição em José Saramago. O essencial e outros ensaios. Lisboa: Imprensa Nacional-Casa da Moeda, 1999.

Artigo recebido em: 22 de Agosto de 2012. Artigo aprovado em: 21 de Novembro de 2012. 